\title{
Comparison of the seasonal cycle of tropical and subtropical precipitation over East Asian monsoon area
}

\author{
LI Yaodong ${ }^{a}$, ZHANG Guojie ${ }^{\text {a }}$, HUANG Bing a and SHI Xiaokang ${ }^{\text {a }}$ \\ ${ }^{a}$ Institute of Aviational Meteorology of Beijing, Beijing, 100085, China \\ Email: lyd@mail.iap.ac.cn
}

\begin{abstract}
The East Asian monsoon includes the tropical monsoon and subtropical monsoon. They are different systems, and the formation mechanisms and major weather systems are not similar, and thus, the structures and characteristics of the associated tropical and subtropical monsoon rainfall and precipitation differ. The properties of precipitation can indicate thermodynamic and dynamic structures and cloud microphysics, and can reflect many characteristics associated with the onset and variation of monsoon, so is the focus of this paper.
\end{abstract}

Four regions (one for tropical monsoon, three for subtropical monsoon) are selected. The components of precipitation (i.e., convective and stratiform rain) are studied by using 10-year (1998-2007) Tropical Rainfall Measuring Mission (TRMM) precipitation radar (PR) rain products (2A25). The results show that the convective rain contribution in the tropical monsoon region $\left(10^{\circ}-20^{\circ} \mathrm{N}\right)$ is much higher than that in the subtropical monsoon regions $\left(20^{\circ}-35^{\circ} \mathrm{N}\right)$. Time series of rainfall, rain probability and rain ratios over each region are analyzed to study the seasonal variability of tropical and subtropical monsoon. Results show that after East Asian summer monsoon onset, rapid increases in convective, stratiform and total rainfall occur in all the four regions. The percentage of convective rain increases significantly in the three subtropical monsoon regions after monsoon onset, but decreases in the tropical monsoon region. TRMM PR observations show that there is no striking difference in the temporal variability in either the rain amount or probability between the East Asian tropical and subtropical monsoon; however, the associated convective rain contribution is significantly different, and East Asian tropical and subtropical monsoon precipitations can thus be separated according to the ratios of convective and stratiform precipitation.

Intergovernmental Panel on Climate Change (IPCC) Coupled Model Inter-comparison Project phase 3 (CMIP3) general circulation model (GCM) rainfall simulation results (1980-1999) are evaluated against 10year TRMM observations. The results show that the GCMs have a better simulation of the subtropical monsoon regions $\left(20^{\circ} \mathrm{N}-35^{\circ} \mathrm{N}\right)$ than the tropical region, with a consistent variability of convective rain relative to the TRMM observations, during the convective rainfall surge after the monsoon onset, with about $10 \%$ deviation. But the GCM simulated convective rain fraction is generally overestimated in East Asia. The largest precipitation biases are found in the tropical monsoon region $\left(0^{\circ}-20^{\circ} \mathrm{N}\right)$, where there is more than $30 \%$ deviation for convective rain relative to TRMM observations. The TRMM rain measurements indicate that the contribution of convection precipitation in the tropical monsoon region falls considerably after onset of the East Asian monsoon. However, the CMIP3 GCMs show the opposite. Results from TRMM PR observations demonstrate that convective precipitation and stratiform precipitation have similar spatialtemporal distribution patterns and are closely correlated in both subtropical and tropical regions, but the GCMs simulate a small coefficient and even a negative correlation over tropical region. Current GCMs significantly underestimate stratiform rainfall over South China Sea, resulting in poor simulations of total rainfall and latent heat profiles; suggesting that some weather and climate phenomenon are not accurately simulated, and thus there is low confidence in GCM projections of East Asian monsoon. The results suggest that a better GCM parameterization scheme for convective and stratiform rain is needed for improving model simulation of the monsoons.

Keywords: $\quad$ Tropical monsoon, subtropical monsoon, convective precipitation, stratiform precipitation 
LI et al., Comparing study on the seasonal variability of tropical and subtropical precipitation over East Asian monsoon area

\section{INTRODUCTION}

The East Asian monsoon includes the tropical monsoon and subtropical monsoon and directly induces droughts and flooding in China. The East Asian summer monsoon is classically defined as breaking out first in the South China Sea, resulting in tropical monsoon rainfall. It then moves northward to southern China in mid- to late May, leading to the first rainy period in southern China. Later, the subtropical summer monsoon rain belt twice jumps northward, stagnating after each jump, leading to the Meiyu over the Yangtze River and Huai River basin (called the Jianghuai Meiyu) and then the rainy season in northern China (Li et al., 2003). Earlier studies have thus concluded that the subtropical monsoon is the result of the northward propagation of the tropical monsoon. However, recent studies (He et al., 2007 and Zhao et al.,2007) indicate that East Asian subtropical monsoon precipitation is established in the last 10 days of March and stays steady and expands to southern China before the onset of the South China Sea summer monsoon (in mid- to late May), leading to southern China pre-rainy season precipitation. After the tropical summer monsoon onset, the East Asian subtropical monsoon moves northward to northern China from southern China, leading to the late stage of the southern China pre-rainy season precipitation, Jianghuai Meiyu, and the rainy season in northern China. These recent results of He et al. (2007) and Zhao et al. (2007) indicate that the onset of East Asian subtropical monsoon rainfall is earlier than that of tropical monsoon rainfall, and the tropical monsoon rainfall and subtropical monsoon rainfall are in fact separate but interacting systems. This has lead to a deep debate about the East Asian summer monsoon within CMA (Chinese Meteorological Community) on this topic (Liu, 2008). However, no concrete conclusions have been reached. Therefore, understanding the differences between the East Asian tropical and subtropical monsoons is an important scientific subject.

The East Asian tropical monsoon and subtropical monsoon are different systems. Their formation mechanisms and major weather systems are not similar, and thus, the structures and characteristics of the associated tropical and subtropical monsoon rainfall and precipitation differ. Zuo et al. (2004) demonstrated that tropical precipitation is mainly convective rain, depending on the atmospheric stability, while subtropical rain is mostly produced by frontal systems, depending on the condensation resulting from large-scale up-lift. Subtropical rainfall is also closely related to the westerly wind. Precipitation is an important factor in monsoon research, so it is the focus of this paper.

Precipitation is normally classified into convective and stratiform rain using rain properties remotely sensed by satellites. The properties of precipitation can indicate thermodynamic and dynamic structures and cloud microphysics. Li et al. (2012) compared precipitation characteristics before and after the onset of the South China Sea monsoon. Their results show that convective rainfall increases significantly over the South China Sea with the arrival of the summer monsoon; however, the contribution of convective rain to the total obviously decreases. This finding is quite different from previously published conclusions. To better understand the similarities of and differences between tropical and subtropical monsoon rainfall, the components of precipitation (i.e., convective and stratiform rain) are considered in this study. and General circulation model (GCM) simulations from the Coupled Model Inter-comparison Model phase 3 (CMIP3) archive (Meehl et al. 2007) are assessed against Tropical Rainfall Measuring Mission (TRMM) precipitation radar $(\mathrm{PR})$ rain observations.

Owing to the narrow swath of the TRMM PR $(\sim 220 \mathrm{~km})$, long-term TRMM observations are employed in obtaining robust climatic characteristics of precipitation (Hu et al., 2013). In this article, 10-year (1998-2007) TRMM PR rain products (2A25) are used to determine properties of convective and stratiform rain (Fu et al., 2003). Convective and stratiform precipitation in the CMIP3 dataset simulated using the 24 GCMs under the condition of $20 \mathrm{c} 3 \mathrm{~m}$ is also investigated. The GCMs are detailed at http://www-pcmdi.llnl.gov/. 20c3m is designed to simulate long-term modern conditions (18501999). The 20-year period (1980-1999) in 20c3m was compared with the TRMM observations.

\section{VARIABILITY IN TROPICAL AND SUBTROPICAL EAST ASIAN MONSOON RAINFALL AND RAIN PROBABILITY}

The four regions selected for this study are referred to as Jianghuai $\left(110^{\circ}-120^{\circ} \mathrm{E}, 28^{\circ}-35^{\circ} \mathrm{N}\right)$, southern China $\left(110^{\circ}-\right.$ $\left.120^{\circ} \mathrm{E}, 20^{\circ}-28^{\circ} \mathrm{N}\right)$, the South China Sea $\left(110^{\circ}-120^{\circ} \mathrm{E}, 10^{\circ}-\right.$ $20^{\circ} \mathrm{N}$ ), and Jiangnan $\left(110^{\circ}-120^{\circ} \mathrm{E}, 24^{\circ}-30^{\circ} \mathrm{N}\right)$ (Figure 1$)$. The South China Sea represents the tropical monsoon region, and

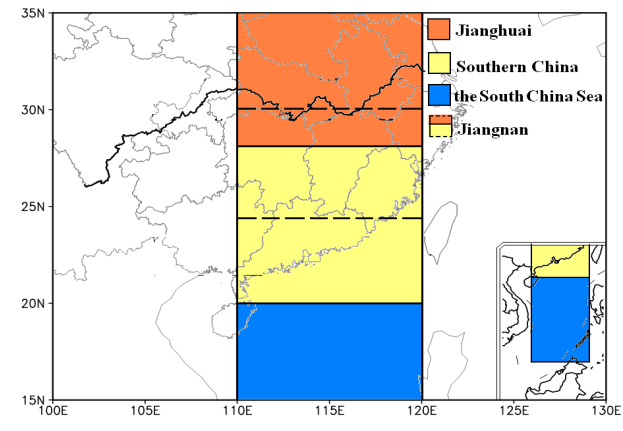

Figure 1. The selected four regions. 
LI et al., Comparing study on the seasonal variability of tropical and subtropical precipitation over East Asian monsoon area

other three represent subtropical monsoon regions. The mean annual cycle of East Asian monsoon convective and stratiform rainfall, total precipitation, and rain probability over $110^{\circ} \mathrm{E}-120^{\circ} \mathrm{E}$ are presented in Figure 2. The rain probability, defined as the ratio of the area of rainfall to the total observation area, reflects the probability of any kind of precipitation. It is evident that convective and stratiform precipitation over southern China $\left(24^{\circ} \mathrm{N}-30^{\circ} \mathrm{N}\right)$ gradually moves southward from March to the onset of the summer monsoon in the South China Sea. The subtropical monsoon rain belt starts to move northward after the onset of the South China Sea monsoon. The rain belt reaches the Yangtze River and Huai River basin (Jianghuai basin) in mid- to late June, thus establishing the Jianghuai Meiyu. This result is consistent with the results of previously published studies (Zhao et al., 2007). In addition, convective precipitation and stratiform precipitation have similar temporal and spatial distributions. When convective rainfall increases (decreases), stratiform rainfall increases (decreases); i.e., they are always closely correlated.

The temporal variations in convective, stratiform and total precipitation are shown in Figure 3. It is obvious that there are consistent rapid increases in convective, stratiform and total precipitation over the four areas after the arrival of the East Asian monsoon.

Figures 2 and 3 clearly present a rapid increase in convective, stratiform and total rainfall after the onset of the East Asian monsoon. It is also evident that the tropical monsoon rain and subtropical monsoon rain are similar in terms of temporal variations in rain intensity and probability.

\section{RATIOS OF CONVECTIVE AND STRATIFORM PRECIPITATION ANALYSIS}

Figure 4 shows the temporal variations in the ratios of convective and stratiform precipitation over the tropical and subtropical monsoon regions. It is clear that the convective rain contribution in the tropical monsoon region is much higher than that in the subtropical monsoon region. After onset of the East Asian summer monsoon, the percentage of convective rain increases significantly in the subtropical monsoon
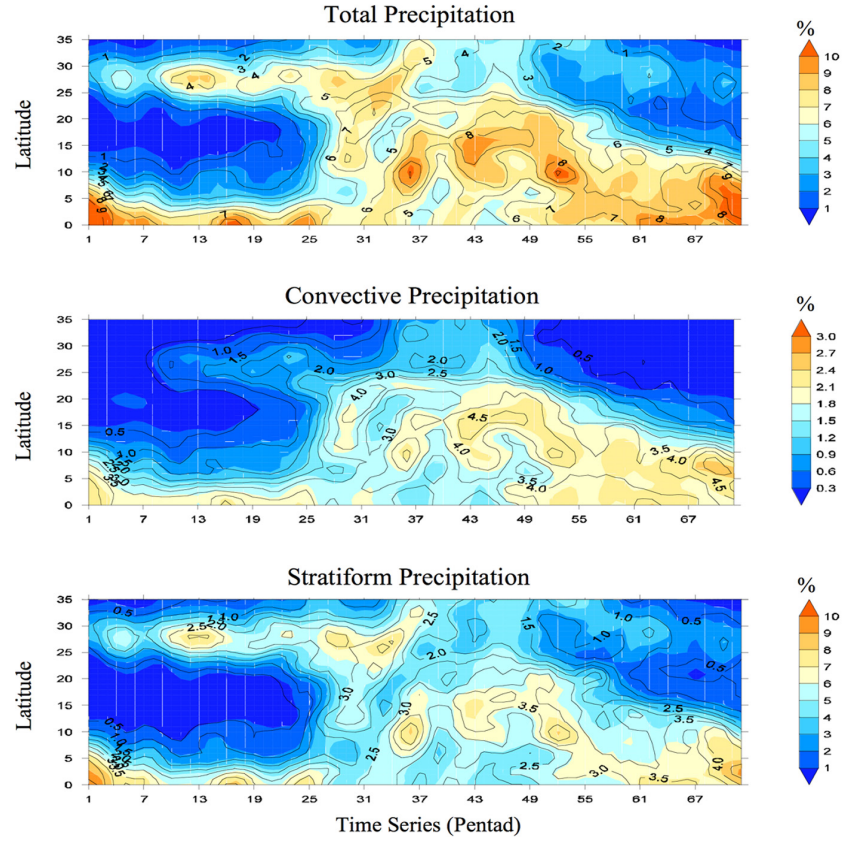

Figure 2. Time-latitude distributions of the East Asian monsoon surface rain intensity (contours in $\mathrm{mm}$ $\mathrm{d}^{1}$ ) and rain probability (shaded areas in \%) averaged over $110^{\circ}-120^{\circ} \mathrm{E}$ for convective precipitation, stratiform precipitation and total precipitation.
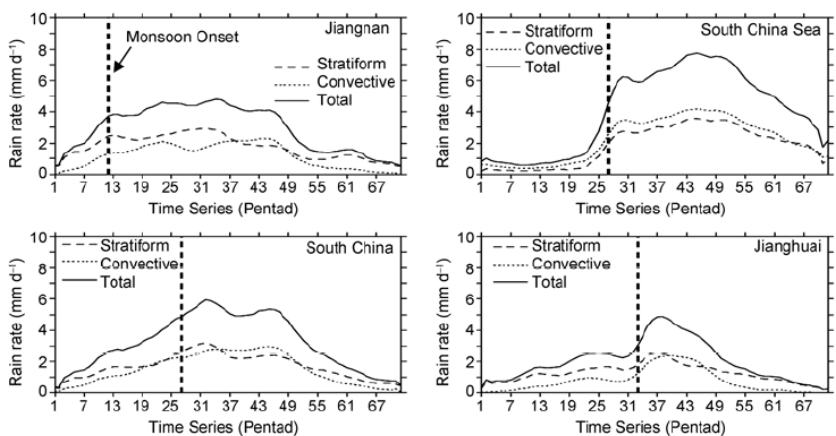

Figure 3. Time series of convective, stratiform and total precipitation over Jiangnan, the South China Sea, South China, and Jianghuai. The heavy dashed line marks the mean monsoon onset date for each region.

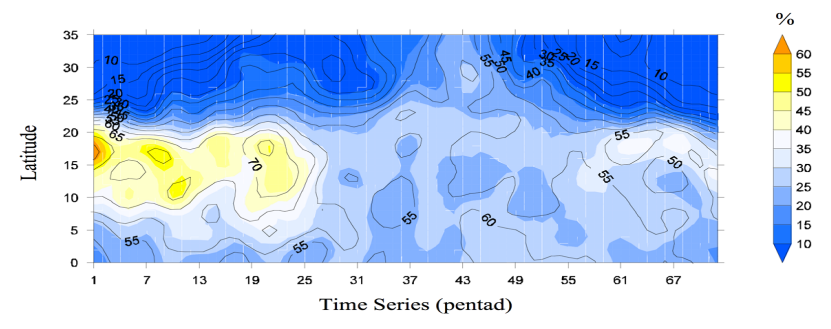

Figure 4. Time-latitude evolution of the convective rainfall contribution (contours in \%) to total precipitation averaged over $110^{\circ}-120^{\circ} \mathrm{E}$. The shading indicates the ratio of the convective-rain area to the total rain area $(\%)$. 
LI et al., Comparing study on the seasonal variability of tropical and subtropical precipitation over East Asian monsoon area

region, but decreases in the tropical monsoon region.

Similar to Figure 3, Figure 5 shows the time series of the ratios of the rain area and rainfall of convective rain to the total rain area and total rainfall over Jiangnan, the South China Sea, southern China, and the Jianghuai region. Consistent temporal variations in convective precipitation are evident over Jiangnan, southern China, and the Jianghuai basin; i.e. the ratio increases significantly as the monsoon propagates northward and decreases as the monsoon retreats. However, this feature is not observed for the South China Sea; i.e., the ratio decreases as the monsoon moves northward.

In summary, there is no striking difference in the temporal variability in either the rain amount or probability between the East Asian tropical and subtropical monsoons; however,

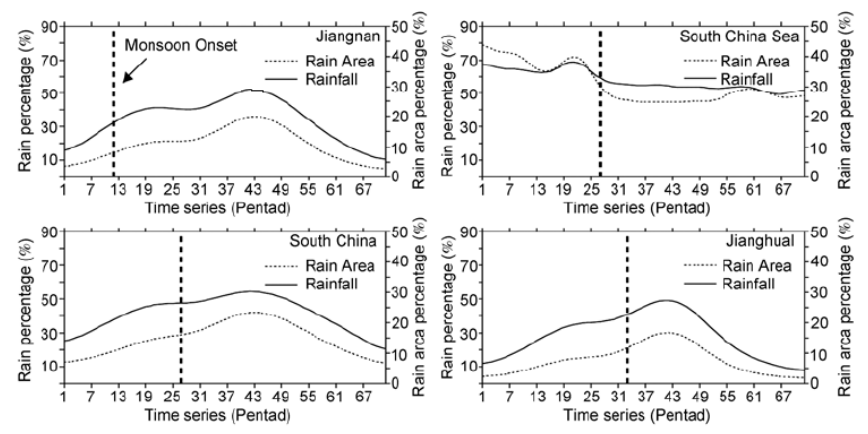

Figure 5. Mean annual ratio (\%) of the convective-rain area and rainfall to total rain area and rainfall respectively over Jiangnan, the South China Sea, southern China, and Jianghuai. The heavy dashed line indicates the monsoon onset date over each region. the associated convective rain contributions are significantly different, and East Asian tropical and subtropical monsoon precipitation can be separated according to the ratios of convective and stratiform precipitation.

\section{EVALUATION OF GCM SIMULATIONS OF THE RATIOS OF EAST ASIAN MONSOON CONVECTIVE AND STRATIFORM PRECIPITATION}

Convective precipitation and stratiform precipitation are the two main components of total rainfall. The ability to simulate correctly the ratios of convective and stratiform precipitation directly affects the GCM's capacity to simulate total rainfall. Current GCMs significantly underestimate stratiform rainfall (Lin et al. 2004), resulting in poor simulations of total rainfall and latent heat profiles; subsequently, lowering the confidence in climate projections of MJO Madden-Julian Oscillation (MJO), Intraseasonal Oscillation (ISO), and Intertropical Convergence Zone (ITCZ). Here we evaluate the seasonal cycle of rainfall against the latest TRMM observations and examine the seasonal cycle in precipitation.

\subsection{Comparison between simulated precipitation and TRMM measurement}

TRMM PR rain type classification is based on the combination of horizontal and vertical profile methods. In the vertical method, a rain TRMM PR pixel is classified as stratiform if its reflectivity has a bright band, and a rain pixel is defined as convective when its maximum reflectivity is greater than $39 \mathrm{dBZ}$ without the bright band. The horizontal method is based on the horizontal convective-stratiform separation scheme. A detailed description of TRMM PR rain type classification can be found in articles written by Arakawa et al. (2007) and Yang et al.(2008). The convective rain is caused by convective instability, while the stratiform rain is due to condensation resulting from large-scale uplift (Arakawa 2004). To assess the capability of the GCMs in simulating accurately the ratios of East Asian monsoon convective and stratiform precipitation, we compare outputs from 24 CMIP3 GCMs and TRMM PR rain data. The results will assist us to identify potential issues with GCMs and to provide useful information for future developments.

Similar to Figures 2 and 4, Figure 6 presents the mean time-latitude distributions of the East Asian monsoon convective precipitation contribution to total rainfall averaged over $110^{\circ}-120^{\circ} \mathrm{E}$ obtained from TRMM observations and the averaged result for the 24 GCMs. (Each CMIP3 GCM has a similar distribution pattern, and thus, we do not need to discuss them individually.) The simulated convective rain fraction is generally overestimated. The worst area is the tropical monsoon region $\left(0^{\circ}-20^{\circ} \mathrm{N}\right)$, where there is more than $30 \%$ deviation for convective rain relative to TRMM observations. The TRMM rain measurements indicate that the contribution of convection precipitation in the tropical monsoon region falls considerably after onset of the East Asian monsoon; however, the CMIP3 GCMs show the opposite. In the subtropical monsoon region $\left(20^{\circ} \mathrm{N}-35^{\circ} \mathrm{N}\right)$, the GCMs have better simulation ability; there is consistent variability of convective rain relative to the TRMM observations, in terms of the convective rainfall surge after the monsoon onset, with only $10 \%$ deviation. 
LI et al., Comparing study on the seasonal variability of tropical and subtropical precipitation over East Asian monsoon area

To further study the ability of GCMs to simulate the East Asian monsoon rainfall, the TRMM and CMIP3 GCM convective rain time series are compared over Jiangnan, the South China Sea, southern China, and the Jianghuai basin (Figure 7). It is seen that the simulated convective rain contribution is generally higher than the TRMM PR measurements. However, the GCM rain simulation captures the main feature of the temporal variation in the convective rain contribution over Jiangnan, southern China, and the Jianghuai basin. The contribution of convective precipitation first increases from January to August and then decreases from September to December. The seasonal variation in the convective precipitation contribution is simulated correctly over these areas. The GCMs fail to capture the variability of the convective rain contribution over the South China Sea in terms of the convective rain contribution magnitude and seasonal variation. The GCM-simulated convective rain fraction is overestimated by up to and exceeding $30 \%$, and it does not present the gradual decrease in the convective rain contribution from January to December observed by the TRMM PR.

Figures 6-7 show that the GCMs apply the same model design to simulate the convective precipitation fractions over tropical and subtropical monsoon regions, and thus, the simulated East Asian monsoon convective rain seasonal variation has similar temporal variations over tropical and subtropical regions. The TRMM PR observations show different seasonal variations in convective precipitation over tropical and subtropical regions. The results suggest that the mechanism of the East Asian monsoon convective and stratiform precipitation might differ over tropical and subtropical regions. If the mechanisms are the same, we have limited understanding of their properties. Other parameters in the GCM simulations, such as the latitude difference and sea and land distribution, should be considered in future work.

\subsection{Possible reasons for the deficiency of GCM stratiform precipitation simulations}

Results from TRMM PR observations (Figure 2) demonstrate that convective precipitation and stratiform precipitation have similar spatial-temporal distribution patterns and are closely correlated. Figure 8 presents the distributions of correlation coefficients between monthly convective and stratiform precipitation obtained from TRMM PR and CMIP3 GCM models over Southeast Asia. It is evident there is a significantly positive relationship between the observed convective and stratiform precipitation in TRMM. The simulated convective precipitation and stratiform precipitation are strongly correlated over the Bay of Bengal and surrounding regions, and the Indonesia-Philippine region; however, a small coefficient and even negative 
LI et al., Comparing study on the seasonal variability of tropical and subtropical precipitation over East Asian monsoon area

correlation are obvious over the South China Sea, eastern China, and the northwestern Pacific. The area for which the simulated correlation has a $90 \%$ significance level is much smaller than the area of TRMM PR measurements. Thus, the GCMs have difficulty in accurately simulating the actual relationship between convective and stratiform precipitation.

Many factors could affect a GCM's ability to correctly simulate stratiform and convective rain. A main factor is the definition of convective and stratiform rain in the GCM. GCM convective precipitation is produced by atmospheric convective instability, while stratiform rain results from condensation resulting from atmospheric uplift. Thus, convective rain and stratiform rain are classified on the basis of two different and uncorrelated mechanisms (Arakawa 2004). In deed, as shown by TRMM PR observations (Figures 9 and 10), stratiform rain always accompanies convective rain as discussed by Houze (1997). Therefore, further improvements of GCM parameterizations of convective and stratiform rainfall are needed.

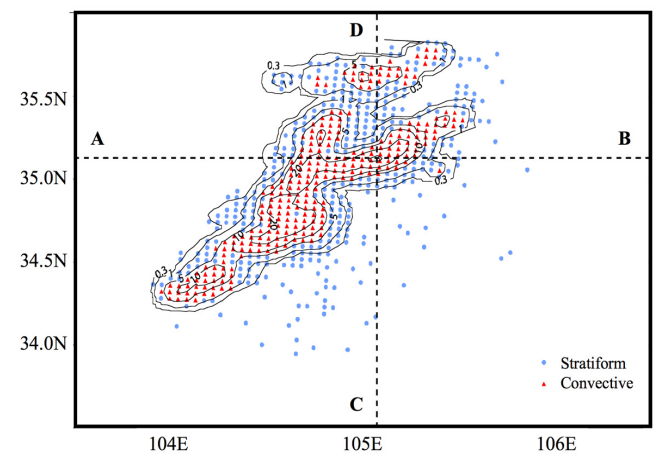

Figure 9. Horizontal distribution of surface rain intensity (contours in $\mathrm{mm} \mathrm{h}^{-1}$ ) for a TRMM PR case (orbit 13476). Cross sections A-B and C-D are selected for study in Figure 10.

\section{CONCLUSIONS}

This study analyzed the seasonal variations in convective and stratiform precipitation over the East Asian monsoon region using 10-year (19982007) TRMM PR rain products and CMIP3 model $20 \mathrm{c} 3 \mathrm{~m}$ datasets. A GCM's ability to simulate convective and stratiform precipitation over East Asian monsoon tropical and subtropical regions was also evaluated.

The results confirm that the East Asian monsoon tropical/subtropical convective and stratiform precipitation increase significantly after the summer monsoon onset. The contribution of convective precipitation decreases over the tropical region, while
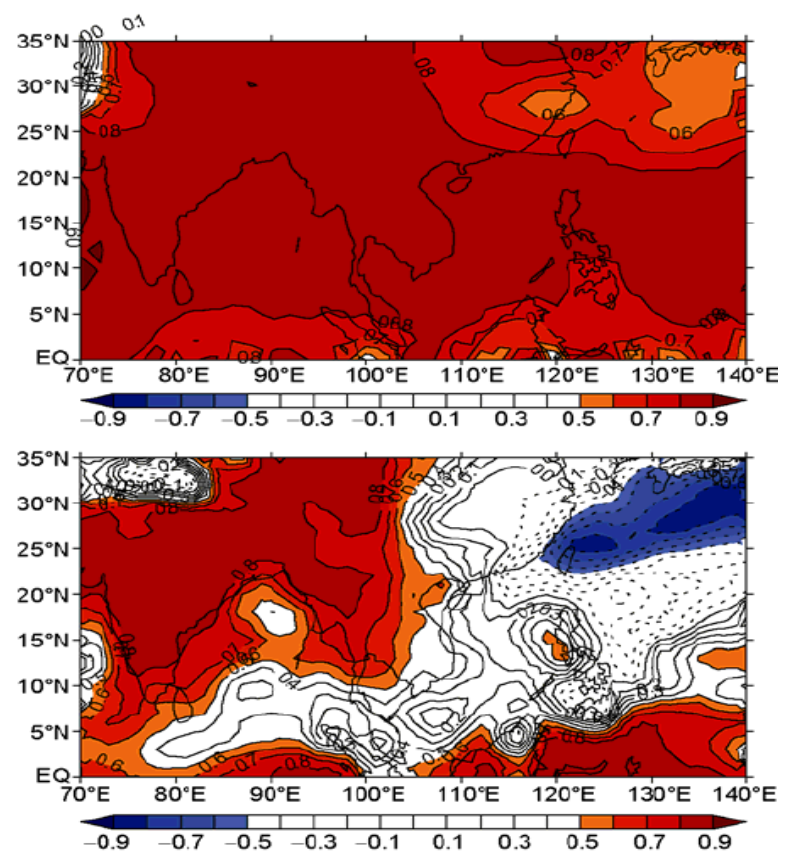

Figure 8. Distributions of the coefficient of correlation between monthly convective and stratiform precipitation obtained from the TRMM PR (top) and CMIP3 (bottom) over Southeast Asia. The shaded areas indicate a confidence level higher than

90\%. The solid and dashed contours represent positive and negative coefficients, respectively.

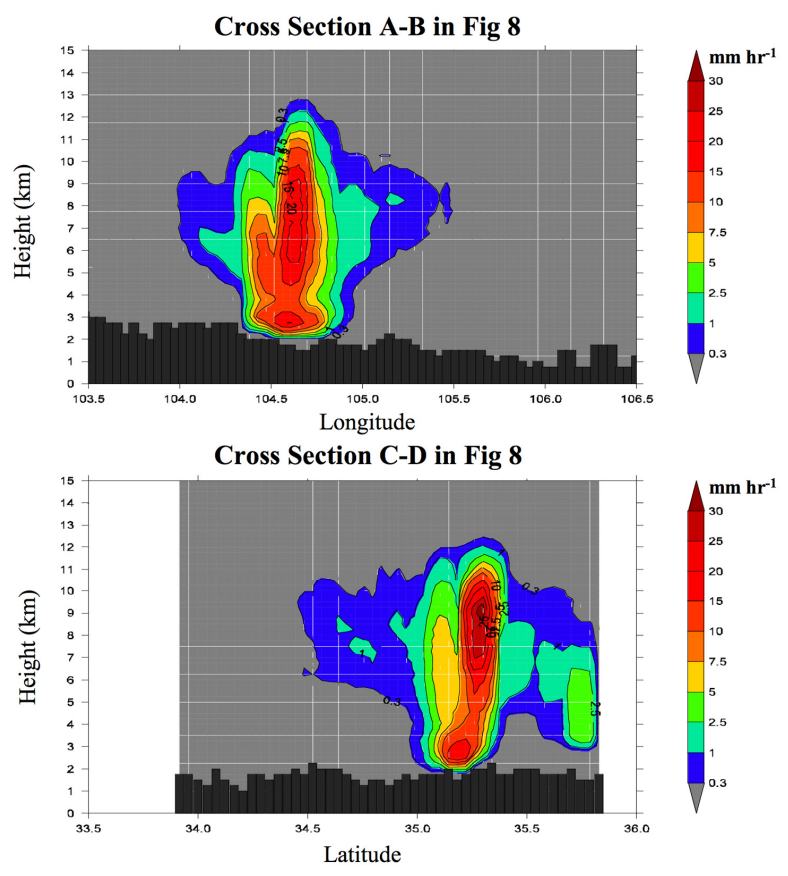

Figure 10. Vertical rain profiles for the two cross sections selected in Figure 9. 
LI et al., Comparing study on the seasonal variability of tropical and subtropical precipitation over East Asian monsoon area

it increases over the subtropical area.

CMIP3 GCMs generally simulate the high contributions of convective rain to the total rainfall over the East Asian monsoon region, particularly in the tropical area, with an overestimation of more than $30 \%$ relative to the TRMM PR measurements. The seasonal variation in the simulated convective rain contribution over the tropical region is opposite to that for the TRMM observations; however, the convective rainfalls obtained from TRMM PR and GCM simulations are in a good agreement over the subtropical region in terms of the convective rain contribution magnitudes and seasonal variations.

This study, based on TRMM PR observations, demonstrates that convective precipitation and stratiform precipitation often occur simultaneously; i.e. they have a significantly positive correlation. However, the CMIP3 GCMs cannot properly present the observed correlation between convective and stratiform precipitation, which indicates that GCMs have deficiencies in correctly simulating the stratiform precipitation. The results here suggest that a better GCM parameterization scheme for convective and stratiform rain is needed for future development.

\section{ACKNOWLEDGMENTS}

This work was supported by the National Natural Science Foundation of China under Grant Nos. 41175046 and 41205009 .

\section{REFERENCES}

Arakawa A. (2004). The cumulus parameterization problem: Past, present, and future. J Clim, 17, 2493-2525.

Arawaka J., Iguchi T., and Okamoto K. (2007). Rain type classification algorithm. Measuring precipitation from space: EURAINSAT and the Future. In: Levizzani V, Bauer P, Turk F J, eds. Heidelberg: Springer, 213-224.

Fu Y. F., and Liu G. S.(2003). Precipitation Characteristics in Mid-Latitude East Asia as Observed by TRMM PR and TMI. J Meteorol Soc Jpn, 81, 1353-1369.

He J. H, Qi L., Wei J., and Chi Y. Z.(2007). Reinvestigations on the East Asian subtropical monsoon and tropical monsoon (in Chinese). Chin J Atmos Sci, 31, 1-9.

Houze R. A.(1997). Stratiform precipitation in regions of convection: A meteorological paradox. Bull Amer Meteor Soc, 78, 2179-2196.

Hu L., Li Y. D., and Deng D. F. (2013). An investigation into the relationship between rain surface rainrate and rain depth over east Asia. Adv Atmos Sci, 30, 142-152.

Li J. P., and Zeng Q. C.(2003). A unified monsoon index. Geophys Res Lett, 29, 1151-1154.

Li Y. D., Song M. K. and Hu L.(2012). A study on the precipitation characterics over the South China Sea before and after the monsoon onset. Journal of Tropical Meteorology, 18,1-10.

Lin J, Mapes B, and Zhang M. H.(2004). Stratiform precipitation, vertical heating profiles, and the MaddenJulian Oscillation. J Atmos Sci, 61, 296-309.

Liu Z. X.(2008). The seminar of East Asian tropical monsoon was open in Beijing (in Chinese). Acta Meteorol Sin, 66, 478.

Meehl, G.A., Covey, C., Delworth, T., Latif, M., McAvaney, B., Mitchell, J.F.B., Stouffer, R.J. and Taylor, K.E. 2007. The WCRP CMIP3 multimodel dataset - A new era in climate change research. Bulletin of the American Meteorological Society, 88: 1383-1394.

Yang S., and Smith E. A.(2008). Convective-stratiform precipitation variability at seasonal scale from eight years of TRMM observations: Implications for multiple modes of diurnal variability. J Clim, 21, 40874114.

Zhao P., Zhang R. H., and Liu J. P.(2007). Onset of southwesterly wind over eastern China and associated atmospheric circulation and rainfall. Clim Dyn, 28, 797-811.

Zuo R. T., Zeng Q C, and Zhang M.(2004). A numerical simulation of monsoon and the correlation between monsoon and westerlies (in Chinese). Chin J Atmos Sci, 28, 7-22. 